\title{
Barriers to HIV Testing among Adolescents and Young Adults in Harare City, Zimbabwe
}

\author{
Article by Notion Gombe ${ }^{1,2}$, Nicholas Midzi ${ }^{3}$ \\ ${ }^{1}$ Public Health, Texila American University, Guyana, South America \\ ${ }^{2}$ Department of Community Medicine, University of Zimbabwe \\ ${ }^{3}$ Department of Medical Microbiology, University of Zimbabwe \\ E-mail:ntgombe@gmail.com ${ }^{1}$,midzinicholas@gmail.com ${ }^{3}$
}

\begin{abstract}
The HIV prevalence in the Zimbabwean population aged 15-49 years remains high (15.2\%). Most adolescents do not know their HIV status despite knowing a place to get tested. We determined barriers to HIV testing and counseling (HCT) among sexually active adolescents and young adults in Harare City

We conducted a cross-sectional study among sexually active adolescents and young adults. Data were collected using a pretested self-administered questionnaire. Information was collected on individual characteristics, HIV testing acceptance, risk behaviors and reasons for having never been tested. Epi-Info 7 was used to analyze data. Chi-square tests and logistic regression models were used to assess independent determinants for not testing for HIV. Statistical significance was set at $p<0.01$.

A total of 427 adolescents and young adults were recruited. The majority (56.9\%) were female. Of these, 186(43.6\%) had never tested for HIV. Participants listed not knowing where to get tested (60.8\%), low risk perception (29\%), never having been offered a test(21.5\%), fear of a positive result(16.1\%), being embarrassed (10.2\%), parents who will not allow (7.5\%), failure to afford consultation fees(5.9\%), and being worried about health worker confidentiality(5.9\%) as reasons for not having been tested. In multivariate analysis being afraid of a positive result [aOR=0.07; 95\%CI (0.01-0.30)] and being male [aOR=0.43; 95\%CI (0.23-0.80)] were independently associated with never having had an HIV test.

Barriers to HIV testing identified in this study can be easily resolved by applying innovative approaches tailored to increase access to and acceptance of HIV-testing services among the adolescent and young adult populations.
\end{abstract}

Keywords: Adolescents, HIV Testing, Correlates, Barriers, Harare City.

\section{Introduction}

HIV Counseling and Testing (HCT) facilitates early diagnosis for HIV positive persons which helps reduce the risk of further transmission, provides access to care and treatment, while motivating people who test HIV negative to maintain their negative status (Day et al. 2003:665; Peltzer, Matseke, Mzolo, \& Majaja, 2009:2; Subramanian, Gupte, Mathai, Boopathi, \& Dorairaj, 2008:26). This suggests that HCT is vital for both knowledge of one's HIV status and HIV prevention. However, there are still people who have no knowledge of their HIV status.

In Zimbabwe according to the Zimbabwe Demographic Health Survey (2010/11) the HIV prevalence rate for the young people between the ages of 15-24 is 5, 5\%. According to the World Bank indicators the prevalence of HIV in males and females aged 15-24 in Zimbabwe is $4.8 \%$ and $7.0 \%$ respectively showing that women are disproportionately affected.

As adolescents and young adults are a key population, many barriers arise because of their vulnerability on a personal, social and policy level. The vulnerability of adolescents from key populations is profoundly compounded by severe social stigma and harsh, poorly informed, legal, and policy regulations and law enforcement practices that criminalize their behaviors and foster discrimination and 
DOI: $10.21522 / \mathrm{TIJPH} .2013 .06 .02 . A r t 008$

ISSN: $2520-3134$

violence (Idele et al., 2014). These factors hinder access to critically needed health services and other HIV prevention, treatment, protection, care, and support interventions.

In Zimbabwe literature on barriers to testing among HCT non-users is limited. However studies have been done elsewhere. Peltzer et. al (2013) in a South African cross-sectional population-based household survey identified self-perceived adolescent barriers to HIV testing such as stigma attitudes and discrimination; a low perception of HIV risk; (Govindasamy et al., 2015) In addition other studies found the fear of knowing and living with a sero positive status; having never been offered testing before; and administrative complications as barriers to adolescent HIV testing (Idele et al., 2014; Baral et al., n.d.). Adolescence provides a window of opportunity in which to intervene early and these barriers need to be addressed when coming up with service delivery models for this key population.

This study sought to determine barriers to HCT among sexually active adolescents and young adults in Harare City.

\section{Methods}

A cross-sectional study was conducted in Harare City and the study participants comprised of adolescents and young adults aged 13-24 years. For purposes of this study a resident of Harare City was classified as someone who has lived in Harare for at least three months. All those who fell within the required age range (13-24 years), able to speak and read English or Shona were eligible to participate. Conversely men and women who fell outside the 13-24 years age range and visitors to Harare metropolitan province were excluded from participating in the study. Adolescents under age 16 who met the inclusion criteria but whose parents did not provide consent were to be excluded. Assuming an error risk of 1.96 and a proportion $(\mathrm{P})$, of those tested for HIV (52.2\%) from a previous study conducted by Pelzer et al (2013) in South Africa and margin of error of 5\%, we obtained a minimum sample size of 422 after factoring in $10 \%$ attrition rate.

Data were collected using a pretested self-administered questionnaire. Information was collected on individual characteristics, HIV testing acceptance, risk behaviors and reasons for having never been tested. Check codes, and legal values were used to reduce errors of data collection and entry. Data were cleaned for errors and inconsistencies before analysis. Data were analyzed using Epi Info 7 statistical package to generate means, frequencies, proportions, prevalence odds ratios (POR), and their corresponding 95\% confidence intervals (CI). PORs excluding the null value (1) in the $95 \%$ confidence interval were considered statistically significant. We conducted stratified analysis to check for effect modification and to control for confounding. Factors associated with ever being HIV-tested were determined using multivariate logistic regression.

To ensure protection of study participants, permission was sought from Harare City Council institutional review board and the Medical Research Council of Zimbabwe (Application number: MRCZ/A/2216). Further, informed written consent was obtained from adolescents age 16 and older and adolescent assent and parental/guardian consent was obtained for those aged $13-15$ years. Consent was obtained after explaining the purpose of the study, and assuring confidentiality. Confidentiality was maintained throughout the study by not including the participants' names from the questionnaires. In addition the questionnaire was self-administered owing to the sensitive nature of the questions.

\section{Results}

\section{Sample characteristics}

Socio demographic characteristics of study participants are reported in Table 1. Of the 427 participants enrolled into this study, 186 had never tested for HIV. Of these 186 participants, the majority (79\%) had attained secondary education and the least $(3.8 \%)$ were those who had never been to school. Students comprised $68.8 \%$ of the population followed by those not employed at $23.7 \%$. High density dwellers accounted for $50.5 \%$ of the study population compared to $49.5 \%$ from the low density suburbs. Majority $(81.2 \%)$ of participants were single. 


\section{Barriers to HIV testing}

Reasons for not testing for HIV are reported in Table 2. Of the total respondents $(n=427), 43.6 \%$ $(\mathrm{n}=186)$ reported never having had an HIV test (Table 2). The most common reason given for not having been tested was not knowing where to get tested (60.8\%). Other reasons given by the participants included perceiving oneself not to be at risk (29.0\%) and having not been offered the test (21.5\%), being afraid of a positive result and being embarrassed were reported by both sexes in almost identical proportions. The list reported reasons were inability to pay fees and being worried about confidentiality reported by $5.9 \%$ respectively.

\section{Bivariate analysis}

Table 3 shows bivariate analysis of barriers to HIV testing in Harare City. A number of factors were associated with ever being tested for HIV in this population of adolescents and young adults. Participants who reported fearing a positive result $[\mathrm{OR}=0.07 ; \mathrm{p}<0.001$ ), having parents who would not allow them to test $(\mathrm{OR}=0.06 ; \mathrm{p}<0.001)$, having attained only primary education $[\mathrm{OR}=0.53 ; \mathrm{p}=0.028)$, being aged less than 18 years $[\mathrm{OR}=0.32 ; \mathrm{p}<0.001)$, being worried about confidentiality $[\mathrm{OR}=0.07 ; \mathrm{p}=0.001)$ and perceiving oneself not to be at risk of contracting HIV [OR=0.01; $<<0.001$ ) were less likely to be tested for HIV.

\section{Multivariate analysis}

Table 4 shows multivariate analysis of barriers to HIV testing in Harare City. After controlling for confounding, independent barriers for HIV testing and counseling among adolescents and young adults in Harare City were; being afraid of a positive result(Adjusted $\mathrm{OR}=0.07 ; \mathrm{P}<0.001$ ) and being male (Adjusted OR=0.43; $\mathrm{p}=0.008$ ).

\section{Discussion}

The current study sought to determine barriers to HIV testing and counseling among adolescents and young adults in Harare City, Zimbabwe. This information is critical, as promotion of HCT is the first step to getting medical care and treatment that can improve health, save lives, and prevent the spread of HIV (Bekker \& Hosek, 2015). HCT provides an entry point to prevention, care, treatment and support. It contributes to reduction of the stigma and discrimination that surrounds HIV and AIDS.

The barriers to HIV testing observed in this study were varying and are consistent with what was observed in similar studies. Consistent with what was reported by Lopez et al (2005) in a study on barriers and facilitators to adolescent HIV testing never having been offered a test was one of the major reasons for not having been tested. Not knowing where to get tested was the major reason for not having been tested given by participants in this study. This finding is consistent with a study that found the majority of non-testers to be unaware of HIV testing sites (Choi et al. 2006:40). Other notable reasons reported in this study include, perceiving oneself not to be at risk, being afraid of a positive result and being embarrassed reported by both sexes in almost identical proportions. Not knowing where to get tested had the highest combined proportion of about $61 \%$ followed by perceiving oneself not to be at risk reported by $29 \%$ of the participants. The least reported reasons were inability to pay fees and being worried about confidentiality reported by $5.9 \%$ respectively.

Perceiving oneself not to be at risk may be attributed to that most participants (58.6\%) reported not being involved in a sexual relationship with their partners (boyfriend/girlfriend) and this may have negatively affected uptake of HIV testing in this population. However this result must be taken with caution considering that most of the participants were school going children and as such their answers may reflect social desirability bias. In a similar study among Hispanics adults in the United States showed that the most common barrier to not being tested for HIV was considering oneself not to be at risk (Lopez-Quintero, Shtarkshall, \& Neumark, 2005; Kabiru, Beguy, Crichton, \& Zulu, 2011; Njagi \& Maharaj, 2006). 
DOI: $10.21522 / \mathrm{TIJPH} .2013 .06 .02 . A r t 008$

ISSN: $2520-3134$

In another study focusing on reasons for not taking an HIV-test among untested men who have sex with men (MSM), results showed that fear of a positive test result and the perceived consequences thereof, were reported as the most important reasons for not taking an HIV-test among at-risk respondents (Mikolajczak, Hospers, \& Kok, 2006). This is supported by other studies in Ethiopia, South Africa and Thailand, (Addis et al., 20103; Strauss, Rhodes, \& George, 2015; Musumari et al., 2016).

Our study had some limitations. Data on HIV testing were self-reported hence social desirability may have influenced some of the responses from study participants. Furthermore recall bias may not be ruled out completely. However, participants were requested to provide written informed consent only after they were fully aware of the study details and they were assured of confidentiality hence bias may be unlikely.

\section{Conclusion}

In this study several barriers of HCT have been identified, which can guide interventions to improve HCT uptake. The most common reason given for not having been tested was not knowing where to get tested. Other reasons given by the participants included low risk perception and having not been offered the test, being afraid of a positive result and being embarrassed reported by both sexes in almost identical proportions. The least reported reasons were inability to pay fees and being worried about confidentiality reported by $5.9 \%$ respectively.

Overall, the major barriers to HIV testing in the current study seem to be more personal than structural. For instance, fear of getting an HIV positive result, being embarrassed and perceived lack of confidentiality by health workers were all considered as the biggest barriers to HIV testing in this study. These findings are consistent with those found in a systematic review of barriers to HIV testing in Europe (Deblonde et al. 2010:429) where the majority of barriers was perceived to be more personal than health care related.

\section{Tables}

Table 1. Socio-demographic characteristics of adolescents and young adults, harare, zimbabwe, 2017

\begin{tabular}{|l|l|l|l|}
\hline Variable & Tested for HIV n (\%) & $\begin{array}{l}\text { Never tested for } \\
\text { HIV n (\%) }\end{array}$ & Total sample n (\%) \\
\hline Sex & & & \\
\hline Male & $94(39.0)$ & $90(48.4 \%)$ & $184(43.09)$ \\
\hline Female & $147(61.0)$ & $96(51.6)$ & $243(56.91)$ \\
\hline Age-group & & & \\
\hline $13-<18$ & $91(37.8)$ & $121(65.1)$ & $212(49.65)$ \\
\hline $18-<23$ & $117(48.6)$ & $60(32.3)$ & $177(41.45)$ \\
\hline $23-<24$ & $19(7.9)$ & $2(1.1)$ & $21(4.92)$ \\
\hline $24+$ & $14(5.8)$ & $3(1.6)$ & $17(3.98)$ \\
\hline $\begin{array}{l}\text { Level of } \\
\text { education }\end{array}$ & & & $19(4.45)$ \\
\hline $\begin{array}{l}\text { Never been to } \\
\text { school }\end{array}$ & $12(5.0)$ & $7(3.8)$ & $35(8.20)$ \\
\hline Primary & $11(4.6)$ & $24(12.9)$ & $353(82.67)$ \\
\hline Secondary & $206(85.5)$ & $147(79.0)$ & $20(4.68)$ \\
\hline Tertiary & $12(5.0)$ & $8(4.3)$ & $169(39.58)$ \\
\hline Occupation & & & $19(4.45)$ \\
\hline Not employed & $125(51.9)$ & $44(23.7)$ & $18(4.77)$ \\
\hline $\begin{array}{l}\text { Informally } \\
\text { employed }\end{array}$ & $10(4.2)$ & $9(4.8)$ & \\
\hline Formally & $13(5.4)$ & $5(2.7)$ & \\
\hline
\end{tabular}


Texila International Journal of Public Health Volume 6, Issue 2, Jun 2018

\begin{tabular}{|l|l|l|l|}
\hline employed & & & \\
\hline Student & $93(38.6)$ & $128(68.8)$ & $221(51.76)$ \\
\hline Area of residence & & & \\
\hline High density & $188(78.0)$ & $94(50.5)$ & $282(66.04)$ \\
\hline Low density & $53(22.0)$ & $92(49.5)$ & $145(33.96)$ \\
\hline Marital status & & & \\
\hline Single & $170(70.5)$ & $151(81.2)$ & $321(75.18)$ \\
\hline Married & $71(29.5)$ & $35(18.8)$ & $106(24.82)$ \\
\hline
\end{tabular}

Table 2. Reasons reported for having never been tested for HIV among adolescents and young adults in Harare City, Zimbabwe $(\mathrm{n}=186)$

\begin{tabular}{|l|l|l|l|}
\hline & Male $(\mathrm{n}=90)$ & $\begin{array}{l}\text { Female } \\
(\mathrm{n}=96)\end{array}$ & Total (\%) \\
\hline $\begin{array}{l}\text { I do not know where I can get } \\
\text { tested }\end{array}$ & 57 & 56 & $113(60.8)$ \\
\hline I am not at risk & 27 & 27 & $54(29.0)$ \\
\hline Never offered an HIV test & 20 & 20 & $40(21.5)$ \\
\hline I am afraid of a positive result & 16 & 14 & $30(16.1)$ \\
\hline I am embarrassed & 10 & 9 & $19(10.2)$ \\
\hline My parent will not allow me & 5 & 9 & $14(7.5)$ \\
\hline Cannot afford fees & 2 & 9 & $11(5.9)$ \\
\hline $\begin{array}{l}\text { I am worried about } \\
\text { confidentiality }\end{array}$ & 6 & 5 & $11(5.9)$ \\
\hline
\end{tabular}

Table 3. Bivariate analysis of factors associated with never tested for HIV in adolescents and young adults, harare city, zimbabwe, 2017

\begin{tabular}{|l|l|l|l|}
\hline Variable & $\begin{array}{l}\text { Never tested } \\
\text { for HIV } \\
n=186\end{array}$ & POR(95\%CI) & p-value \\
\hline I am not at risk & $\begin{array}{l}53 \\
133\end{array}$ & $0.01(0.00-0.08)$ & $<0.001$ \\
\hline $\begin{array}{l}\text { Yes } \\
\text { No }\end{array}$ & \begin{tabular}{l} 
\\
\hline My parents will not allow me to get tested
\end{tabular} & $0.06(0.01-0.43)$ & $<0.001$ \\
\hline $\begin{array}{l}\text { Yes } \\
\text { No }\end{array}$ & 13 & $0.07(0.02-0.25)$ & $<0.001$ \\
\hline Fear of a positive result & 27 & \\
\hline $\begin{array}{l}\text { Yes } \\
\text { No }\end{array}$ & 159 & $0.07(0.01-0.58)$ & 0.001 \\
\hline I am worried about confidentiality & 10 & \\
\hline $\begin{array}{l}\text { Yes } \\
\text { No }\end{array}$ & 176 & $0.33(0.22-0.49)$ & $<0.001$ \\
\hline Age & 121 & \\
\hline $\begin{array}{l}<18 \\
>18\end{array}$ & 65 & $0.53(0.30-0.94)$ & 0.028 \\
\hline Education level & 31 \\
\hline $\begin{array}{l}\text { Primary and below } \\
\text { Above primary }\end{array}$ & 155 & \\
\hline
\end{tabular}


DOI: $10.21522 / \mathrm{TIJPH} .2013 .06 .02 . A r t 008$

ISSN: $2520-3134$

Table 4 Multivariable model of predictors of HCT in adolescents and young adults, Harare City, Zimbabwe, 2017

\begin{tabular}{|l|l|l|l|}
\hline Term & $\mathrm{aOR}^{1}$ & $95 \% \mathrm{Cl}^{2}$ & $\mathrm{p}$-value \\
\hline $\begin{array}{l}\text { Being afraid of a positive } \\
\text { result }\end{array}$ & 0.07 & $0.01-0.30$ & $<0.001$ \\
\hline Sex(Male) & 0.43 & $0.23-0.80$ & 0.008 \\
\hline
\end{tabular}

\section{References}

[1]. Addis, Z., Yalew, A., Shiferaw, Y., Alemu, A., Birhan, W., Mathewose, B., \& Tachebele, B. (2013). Knowledge, attitude and practice towards voluntary counseling and testing among university students in North West Ethiopia: a cross sectional study. BMC Public Health, 13, 714. https://doi.org/10.1186/1471-2458-13-714

[2]. Baral SD, Poteat T, Strömdahl S, Wirtz AL, Guadamuz TE, Beyrer C. Worldwide burden of HIV in transgender women: a systematic review and meta-analysis. Lancet Infect Dis. 2013; 113(3):214-22. Publisher Full Text

[3]. Bekker, L.-G., \& Hosek, S. (2015). HIV and adolescents: focus on young key populations. Journal of the International AIDS Society, 18(2Suppl 1). https://doi.org/10.7448/IAS.18.2.20076

[4]. CDC. Revised Recommendations for HIV Testing of Adults, Adolescents, and Pregnant Women in Health$\begin{array}{llllll}\text { Care } & \text { Settings. } & \text { (2006). } & \text { Retrieved } & \text { February } & \text { 7, 2018, }\end{array}$ https://www.cdc.gov/mmwr/preview/mmwrhtml/rr5514a1.htm

[5]. Choi, K. H., Lui, H., Guo, Y., Han, L., \& Mandel, J. S. (2006). Lack of HIV testing and awareness of HIV infection among men who have sex with men, Beijing, China. AIDS Education and men who have never tested for HIV. Sexually Transmitted Diseases, 38(5), 419e428. http://dx.doi.org/10.1097/OLQ.0b013e31820369dd.

[6]. Day, J. H., Miyamura, K., Grant, A. D., Leeuw, A., Munsamy, J.,Baggaley, R., et al. (2003). Attitudes to HIV voluntary counselling and testing among mineworkers in South Africa:will availability of antiretroviral therapy encourage testing? AIDS Care, 15, 665e672. http://dx.doi.org/10.1080/0954012030001595140.

[7]. Deblonde, J., De Koker, P., Hamers, F. F., Fontaine, J., Luchters, S., \& Temmerman, M. (2010). Barriers to HIV testing in Europe: a systematic review. European Journal of Public Health, 20(4), 422e432. http://dx.doi.org/10.1093/eurpub/ckp231.

[8]. Govindasamy, D., Ferrand, R. A., Wilmore, S. M., Ford, N., Ahmed, S., Afnan-Holmes, H., \& Kranzer, K. (2015). Uptake and yield of HIV testing and counselling among children and adolescents in sub-Saharan Africa: a systematic review. Journal of the International AIDS Society, 18(1), 20182. http://doi.org/10.7448/IAS.18.1.20182

[9]. Idele, P., Gillespie, A., Porth, T., Suzuki, C., Mahy, M., Kasedde, S., \& Luo, C. (2014). Epidemiology of HIV and AIDS among adolescents: current status, inequities, and data gaps. Journal of Acquired Immune Deficiency Syndromes (1999), 66 Suppl 2, S144-153. https://doi.org/10.1097/QAI.0000000000000176

[10]. Kabiru, C. W., Beguy, D., Crichton, J., \& Zulu, E. M. (2011). HIV/AIDS among youth in urban informal (slum) settlements in Kenya: what are the correlates of and motivations for HIV testing? BMC Public Health, 11, 685. https://doi.org/10.1186/1471-2458-11-685

[11]. Lopez-Quintero, C., Shtarkshall, R., \& Neumark, Y. D. (2005). Barriers to HIV-testing among Hispanics in the United States: analysis of the National Health Interview Survey, 2000. AIDS Patient Care and STDs, 19(10), 672683. https://doi.org/10.1089/apc.2005.19.672

[12]. Mikolajczak, J., Hospers, H. J., \& Kok, G. (2006). Reasons for not taking an HIV-test among untested men who have sex with men: an Internet study. AIDS and Behavior, 10(4), 431-435. https://doi.org/10.1007/s10461-0069068-8

[13]. MOHCC- Zimbabwe National Guidelines for HIV Testing and Counselling in Children and Adolescents (2014). Retrieved January 13, 2018, from https://aidsfree.usaid.gov/sites/default/files/hts_zimbabwe_2014.pdf

[14]. Musumari, P. M., Tangmunkongvorakul, A., Srithanaviboonchai, K., Yungyuankul, S., Techasrivichien, T., Suguimoto, S. P., ... Chariyalertsak, S. (2016). Prevalence and Correlates of HIV Testing among Young People

${ }^{1} \mathrm{aOR}$ is adjusted odds ratio

2 95\% Cl is $95 \%$ confidence interval 
Enrolled in Non-Formal Education Centers in Urban Chiang Mai, Thailand: A Cross-Sectional Study. PLOS ONE, 11(4), e0153452. https://doi.org/10.1371/journal.pone.0153452

[15]. Njagi, F., \& Maharaj, P. (2006). Access to voluntary counselling and testing services: Perspectives of young people. South African Review of Sociology, 37(2), 113-127. https://doi.org/10.1080/21528586.2006.10419150

[16]. Peltzer, K., Matseke, G., Mzolo, T., \& Majaja, M. (2009).Determinants of knowledge of HIV status in South Africa: results from a population-based HIV survey. BioMedCentral Public Health, 9, 174. http://dx.doi.org/10.1186/1471-2458-9-174.

[17]. Strauss, M., Rhodes, B., \& George, G. (2015). A qualitative analysis of the barriers and facilitators of HIV counselling and testing perceived by adolescents in South Africa. BMC Health Services Research, 15(1), 250. https://doi.org/10.1186/s12913-015-0922-0

[18]. Subramanian, Y., Gupte, M. D., Mathai, A. K., Boopathi, K., \& Dorairaj, V. S. (2008). Perception of HIV among attendees at an TD clinic in India. AIDS Care, 20(1), 26e34. http://dx.doi.org/10.1080/09540120701427480. 